\title{
Consulta livre, prévia e informada? Sobre os processos de participação de comunidades quilombolas em licenciamentos ambientais no Brasil
}

Open, prior and informed consultation? The processes of participation of quilombola communities in environmental licensing in Brazil

\section{Sabrina D'Almeida}

Brasil. Universidade Federal Rural do Rio de Janeiro. Professora da Universidade Federal Rural do Rio de Janeiro, pesquisadora do Instituto de Estudos Comparados em Administração Institucional de Conflitos (Universidade Federal Fluminense) e do Centro Brasileiro de Análise e Planejamento. ID ORCID: https://orcid.org/0000-0001-5846-5490.E-mail: sabrina2809@hotmail.com.

\section{Resumo}

A partir de duas situações etnográficas, este artigo procura descrever a maneira pela qual vem se dando o exercício do direito à consulta de comunidades quilombolas em processos de licenciamento ambiental de empreendimentos com potencial de degradação socioambiental. O referido direito se encontra assegurado tanto em normativas nacionais quanto internacionais e, apesar de ser uma conquista fundamental destes grupos, as ações no plano jurídico-legal nem sempre são suficientes para garantir sua efetivação plena. Pretende-se problematizar a relação entre o plano normativo e o das interações sociais - ou seja, lugar onde se dá sua aplicabilidade -, apontando para a desarticulação que se observou entre eles, bem como chamar a atenção para o papel que mediadores e apoiadores que atuam em prol dos direitos quilombolas desempenham na formulação de demandas que serão endereçadas por estes grupos ao Estado e ao empreendedor.

Palavras-chave: Comunidades Quilombolas, Licenciamento Ambiental, Consulta, Convenção 169 da OIT. 


\section{Abstract}

By verifying two ethnographic situations, this article describes how environmental impact assessment processes consider Quilombola community rights to consultation in the course of large projects. This right is assured both in national and international regulations and, although it is a fundamental achievement of these groups, legal actions are not always sufficient to guarantee its full effectiveness. This article thus analyzes the relationship between the normative plan and the plan of social interactions - that is, the place where its applicability is provided - pointing to the disarticulation between them and stressing the role that mediators and supporters who work on behalf of Quilombola rights play in formulating demands that will be addressed by these groups to the government and to entrepreneurs.

Keywords: Quilombola Communities, Environmental Licensing, Consultation, OLT Convention n 169.

\section{INTRODUÇÃO}

As últimas décadas no Brasil foram marcadas por mudanças formais, administrativas, jurídicas e simbólicas no que diz respeito à forma de tratamento que deve ser concedida a grupos etnicamente diferenciados, dentre eles as comunidades remanescentes de quilombos e os povos indígenas. O Estado brasileiro, desde o processo de abertura democrática, em 1988, tem conferido reconhecimento às diferenças identitárias no espaço público no esforço de produzir uma democracia de feição multicultural e pluriétnica cujo princípio basilar é a regra da igualdade que consiste em tratar igualmente cidadãos em suas diferenças (DUMONT, 1966; KYMLICKA, 1995; MOTA, 2014). Indígenas e quilombolas, enquanto minorias que compõem o Estado-Nação até então invisíveis no cenário político nacional (LEITE, 2000), passaram a encontrar abrigo no arcabouço jurídico brasileiro, por meio de leis que asseguram a titulação de seus territórios e o direito de exercerem seus modos de vida e serem formalmente consultados quando previstas medidas legislativas ou administrativas suscetíveis de afetá-los 
diretamente, dentre outros ${ }^{1}$. De acordo com Almeida (2008), a complexidade de elementos identitários foi trazida para o campo das relações políticas, verificando-se uma ruptura profunda com a atitude colonialista homogeneizante que historicamente apagou as clivagens étnicas e a diversidade cultural.

No que se refere ao direito à consulta, o Brasil conta, desde $2011^{2}$, com uma portaria que disciplina a atuação da Fundação Cultural Palmares(FCP) e da Fundação Nacional do Índio (Funai) - órgãos públicos federais encarregados de representar quilombolas e indígenas, respectivamente - nos processos de licenciamento ambiental de empreendimentos com potencial de degradação socioambiental'3 ${ }^{3}$ Quando identificada a presença destes grupos na área de influência de um determinado empreendimento ou atividade, eles devem ser consultados e contemplados com estudos específicos de caracterização e análise de impactos nos seus modos de vida, em suas dinâmicas culturais, econômicas e territoriais. Tal normativa pode ser compreendida como um dispositivo legal em consonância com o contexto e relevante para a consolidação dos direitos diferenciados (FRASER; HONNETH, 2003).

A Convenção 169 da Organização Internacional do Trabalho (OIT) (2011) ratificada pelo Brasil em 2002, é o principal instrumento normativo internacional que oferece inspiração às normativas nacionais no que diz respeito à consulta e à participação dos povos indígenas e comunidades quilombolas na formulação, implementação e avaliação de planos e programas de desenvolvimento nacional e regional que possam afetá-los diretamente ${ }^{4}$.

\footnotetext{
Para mais informações sobre os debates que envolvem os direitos de comunidades quilombolas e o reordenamento jurídico-legal promovido a partir de 1988, ver Arruti (2006), O’Dwyer (2002), Leite (2000, 2008), Almeida (2011).

2 Portaria Interministerial no 419/2011, revogada pela Portaria Interministerial nº 60/2015.

3 Essa atribuição foi transferida recentemente da Fundação Cultural Palmares para o Instituto de Colonização e Reforma Agrária (Incra), constando como competência própria da Diretoria de Governança Fundiária, de acordo com Inciso VII, artigo 13, do Decreto $\mathrm{n}^{\circ}$ 10.252, de 20 de fevereiro de 2020, da Subchefia para Assuntos Jurídicos da Presidência da República. Cabe ressaltar, entretanto, que durante este período de transição a Fundação Cultural Palmares permanece acompanhando alguns processos de licenciamento ambiental, transferindo-os gradualmente para o Incra.

4 De acordo com seu artigo $\mathrm{n}^{\circ} 7$, "sempre que necessário, os governos garantirão a realização de estudos, em colaboração com os povos interessados, para avaliar o impacto social, espiritual, cultural e ambiental das atividades de desenvolvimento planejadas sobre eles. Os resultados desses estudos deverão ser considerados critérios fundamentais para a implementação dessas atividades" (ORGANIZAÇÃO INTERNACIONAL DO TRABALHO, 2011, p. 20).
} 
Esses instrumentos legais atribuem, portanto, legitimidade no espaço público e na esfera pública brasileira, às formas particulares de organização social, política, econômica e cultural de grupos minoritários. Apesar de se constituírem enquanto uma conquista fundamental destes grupos, as ações no plano jurídico-legal nem sempre são suficientes para garantir a efetivação plena deste direito. Com esta afirmação estamos querendo chamar a atenção para o descompasso que se tem observado nos processos de consulta às comunidades quilombolas entre o plano da norma e o plano das interações sociais no qual se dá sua aplicabilidade.

Outros autores, embora voltados a contextos etnográficos distintos do que estamos abordando, já haviam alertado sobre o descompasso entre estes dois planos. O paradoxo legal brasileiro, como o designou Kant de Lima (1995), se caracterizaria por uma ordem constitucional igualitária que, ao ser aplicada, ganha contornos hierárquicos, atribuindo diferentes graus de cidadania às distintas classes de indivíduos. A combinação de princípios constitucionais igualitários e sistema hierarquizado na aplicação das leis no Brasil também foi objeto de reflexão de Cardoso de Oliveira (2002), que, em suas pesquisas, se vale da distinção entre esfera e espaço público, ou seja, entre o plano normativo e o plano da interação propriamente dita. Segundo ele, no Brasil, se verifica uma hegemonia dos valores do liberalismo na esfera pública, dentre os quais a ideia da igualdade de direitos, enquanto no plano das interações cotidianas (espaço público) a perspectiva hierárquica tem precedência. Essa desarticulação entre esfera e espaço público seria a principal responsável pelo déficit de cidadania no Brasil. (OLIVEIRA, 2002, p. 13)

A dessintonia entre estas duas dimensões da vida social (o plano normativo e o plano das interações) pode ser também observada quando nos debruçamos sobre o exercício do direito à consulta de povos indígenas e comunidades quilombolas no âmbito de processos de licenciamento ambiental. Conforme veremos neste artigo, embora no plano jurídico-legal prevaleça o apreço pelo tratamento diferenciado a estes grupos a fim de se garantir o princípio da igualdade - como é o caso do direito à consulta -, 
no plano da prática o que se depreende é a particularização na sua aplicação, ou seja, cada comunidade quilombola se mostra como um caso específico e, como tal, recebe um tratamento particular.

A não literalidade das normas no Brasil, ou seja, a inexistência de protocolos claros que fundamentem previamente as medidas e procedimentos adotados pelos agentes, propicia justamente sua interpretação particularizada, favorecendo a ideia de que cada caso é um caso. $\mathrm{O}$ direito à consulta se apresenta como um caso ilustrativo por meio do qual é possível identificar a fragilidade dos protocolos que deveriam orientar seu exercício.

Diante do exposto, pretende-se tomar duas situações etnográficas para refletir sobre como vem se dando o exercício deste direito e a participação de comunidades quilombolas em processos de licenciamento ambiental, a despeito das normas (nacionais e internacionais) que os orientam, ou melhor, que deveriam orientá-los. Acredita-se que as consultas a esses grupos no âmbito do licenciamento ambiental permitem pensar temas como direitos diferenciados, cidadania, (des)igualdade e a relação entre Estado e sociedade. Como veremos, duas comunidades, situadas na área de influência de um mesmo empreendimento, nas quais foram identificados os mesmos impactos, recebem tratamentos diferenciados na etapa final da consulta, quando são definidas as medidas mitigadoras e compensatórias.

Os dois casos foram selecionados por duas razões. Uma delas está associada ao fato de evidenciarem alguns traços e práticas recorrentes que se têm observado nos processos de consulta a estes grupos. A outra está relacionada ao fato das comunidades terem se relacionado de forma distinta com um mesmo projeto de empreendimento que causaria impactos em seus territórios, o que resultou em desigualdades no acesso ao direito de ser consultado e devidamente compensado pelos impactos. Ou seja, o objetivo aqui é sublinhar os contrastes entre essas duas comunidades quilombolas, na sua forma de interagir com o Estado e com representantes do empreendimento, bem como nas estratégias empregadas para o encaminhamento das demandas que foram surgindo no processo de licenciamento ambiental. Como veremos, a interação de forma permanente e prévia com mediadores provenientes de organizações 
da sociedade civil e de movimentos sociais se constitui como um fator relevante para a compreensão do modo como cada comunidade vai exercer sua participação no processo de consulta, bem como as circunstâncias, sobretudo econômicas, em que se encontravam no momento da chegada do empreendimento.

O período que a análise deste artigo abarca se inicia com as primeiras reuniões informativas realizadas nas duas comunidades situadas no sertão nordestino ${ }^{5} \mathrm{e}$ vai até o protocolo do estudo do componente quilombola (ECQ) e plano básico ambiental quilombola (PBAQ) junto à Fundação Cultural Palmares, momento em que o processo de consulta é finalizado ${ }^{6}$. Os dados que fundamentaram esta análise foram coletados em trabalho de campo e consistem em entrevistas e observações de campo ${ }^{7}$. A descrição etnográfica busca apresentar os contornos que o exercício deste direito vai ganhando ao longo das etapas de consulta, entendida aqui não como um momento pontual, mas enquanto processo que admite avanços, recuos e revisões.

\section{LICENCIAMENTO AMBIENTAL E COMUNIDADES QUILOMBOLAS: ATORES E SEUS PAPÉIS}

Em setembro de 2018, uma empresa privada do setor de energia dá início aos primeiros trâmites que envolvem um processo de licenciamento ambiental de dois empreendimentos que arrematara em leilões públicos em 2017. Um deles se refere à construção de um parque eólico e o outro à instalação de uma linha de transmissão (LT) de 500 quilovolts que atravessaria doze municípios do sertão nordestino ${ }^{8}$.

5 A identidade dos atores será preservada a fim de manter seu anonimato e, por este motivo, os nomes das comunidades quilombolas são fictícios.

${ }^{6}$ O que não significa que as comunidades não pudessem acionar a Fundação Cultural Palmares caso observassem irregularidades no período de execução do PBAQ. O empreendedor, por sua vez, deveria encaminhar relatórios periódicos a este órgão, ao longo de todo o período de execução, com o objetivo de informá-lo sobre o andamento e a efetivação das ações propostas no PBAQ.

7 Que foram possíveis em virtude do trabalho de assessoria prestado pela autora no curso deste processo.

8 A referida linha de transmissão, que nos interessa mais diretamente neste artigo, foi aprovada como Projeto Prioritário de Transmissão de Energia Elétrica, conforme Portaria n 207, da Secretaria de Planejamento e Desenvolvimento Energético do Ministério de Minas e Energia, e está inserida no projeto de expansão da Rede Básica para escoamento do potencial eólico que vem sendo explorado nesta região. 
A empresa responsável, que após o leilão de 2017 passou à condição de concessionária, optou por abrir processos de licenciamento ambiental diferentes para cada empreendimento, sob o argumento, expresso pelo técnico designado para acompanhar o projeto do parque eólico, de que os eles causariam impactos distintos e, portanto, deveriam ser elaborados estudos independentes para cada um deles. Por este motivo, correram, simultaneamente, dois processos no órgão ambiental estadual, bem como na Fundação Cultural Palmares. No âmbito deste artigo nos concentraremos apenas no processo de licenciamento da linha de transmissão, embora em determinados momentos seja necessário nos referirmos ao parque eólico, pois os dois empreendimentos foram projetados próximo um do outro, fazendo com que suas respectivas áreas de influência direta estivessem sobrepostas em determinadas localidades.

Como a Fundação Cultural Palmares era um dos órgãos públicos que devia ser consultado num processo de licenciamento ambiental ${ }^{9}$, em janeiro de 2019 o órgão ambiental estadual encaminha um ofício a esta instituição, solicitando sua manifestação quanto à presença de comunidades quilombolas na área de influência direta da linha de transmissão ${ }^{10}$.

A Fundação Cultural Palmares, por sua vez, encaminha sua resposta ao ofício do órgão licenciador três meses depois, em abril, atestando a existência de três delas: quilombo Paiol Rural, quilombo Paiol Urbano ${ }^{11}$ e quilombo Mumbuca. O primeiro estava na área de influência dos dois empreendimentos, o segundo apenas do parque eólico e o terceiro da

\footnotetext{
9 Segundo a Portaria Interministerial nº6/2015, a Fundação Cultural Palmares era um dos órgãos envolvidos no processo de licenciamento ambiental quando identificadas comunidades quilombolas na área de abrangência do empreendimento. Cabia a este órgão manifestar-se sobre os impactos de empreendimentos ou atividades em áreas quilombolas.

${ }^{10}$ Para que tais comunidades sejam contempladas com estudos específicos, sua distância em relação às linhas de transmissão deve ser de cinco quilômetros, conforme Portaria Interministerial n 60/2015 (BRASIL, 2015). Na prática, esta regra é bastante maleável, haja vista que boa parte das comunidades não possuem RTID, ou seja, seus territórios não se encontram formalmente demarcados e as distâncias em relação ao empreendimento são medidas em relação ao núcleo das comunidades e não a partir de suas fronteiras territoriais.

${ }^{11}$ Este quilombo se originou a partir da migração de famílias do quilombo Paiol Rural, com quem os moradores continuam mantendo estreitos laços de parentesco e compadrio. Algumas famílias chegam a alternar sua residência entre um quilombo e outro.
} 
linha de transmissão. De acordo com algumas normativas que disciplinam o licenciamento ambiental ${ }^{12}$, nos casos em que se identifica a presença de comunidades quilombolas na área de influência de uma atividade ou empreendimento que possa afetá-las, é necessário que elas sejam consultadas e seja elaborado um estudo específico - o ECQ. São eles que subsidiavam a manifestação da Fundação Cultural Palmares (por meio de parecer técnico) junto ao órgão licenciador. Acompanhando o ofício encaminhado a este órgão, e no qual se atesta a existência de comunidades quilombolas, encontra-se o termo de referência específico, elencando as informações que devem orientar a elaboração do $\mathrm{ECQ}^{13}$.

Em março do mesmo ano, enquanto se aguardava a manifestação da instituição acerca da presença de comunidades quilombolas no entorno do empreendimento, o estudo de impacto ambiental (EIA) da LT foi protocolado no órgão ambiental onde foi aberto o processo. Em junho, quando ainda se desenvolviam os trabalhos de campo nas comunidades quilombolas, o órgão licenciador emitiu a licença prévia ao empreendimento, documento que, vale destacar, é recomendado ser emitido apenas depois que o ECQ tiver sido protocolado ${ }^{14}$.

Logo após a manifestação da Fundação Cultural Palmares, ansiosamente aguardada por empreendedor e empresa de consultoria, já se iniciaram os primeiros trâmites para a realização da consulta às comunidades, agendada para ocorrer naquele mesmo mês (abril).

De acordo com a Convenção 169 da OIT, cabe aos governos realizar a consulta de forma prévia, livre, informada e de boa-fé aos povos interessados sobre seu consentimento quando previstas medidas legislativas ou

\footnotetext{
12 Portaria Interministerial no 60/2015; Instrução Normativa da FCP nº 1/2018; Convenção da OIT $\mathrm{n}^{\circ} 169 / 1989$.

13 Dentre as quais: (1) “diagnóstico geral” (dados fundiários, demográficos, históricos, etnográficos, dentre outros); (2) a descrição dos eventuais impactos nos seus modos de vida e em suas dinâmicas econômicas, territoriais e culturais; (3) propostas de medidas e ações mitigatórias, compensatórias e de controle frente aos impactos identificados.

14 Instrução Normativa FCP nº 1/2018.
} 
administrativas suscetíveis de afetá-los diretamente ${ }^{15}$. Não haveria, contudo, uma forma específica de realizá-la que se mostrasse adequada a todos os países e a todas as circunstâncias (NACIONES UNIDAS, 2009). Assim, este documento fornece diretrizes para orientar a consulta - como a de que seja prévia e informada e que se utilizem procedimentos adequados etc. -, mas não determina o seu formato ${ }^{16}$.

A consulta é realizada, ainda conforme a referida convenção, com vistas a chegar consenso sobre os planos ou projetos de gestão que afetem esses povos. Visa-se a negociação entre as várias partes envolvidas (governo, empresa, povos e comunidades tradicionais), com o objetivo de chegar a um acordo que seja aceitável e, sobretudo, que anteceda as decisões sobre as medidas propostas. Isto significa dizer que as consultas devem ser realizadas nas primeiras etapas de elaboração da proposta em questão (DUPRAT, 2014; NACIONES UNIDAS, 2009; ROSSITO et al., 2019) para que estes grupos possam, efetivamente, participar do processo de tomada de decisão, ainda que a consulta possua um caráter consultivo, e não deliberativo.

Embora em boa parte dos casos isso não ocorra, a antecedência da consulta se faz necessária para que os povos e comunidades tradicionais possam, de fato, participar desta negociação e influir no processo de tomada de decisão e não apenas serem informados sobre decisões já tomadas ou em vias de efetivarem-se (NACIONES UNIDAS, 2009), o que revela o grau de importância que a convenção atribui à participação destes grupos.

${ }_{15}$ O que pode envolver distintos contextos, como: reformas constitucionais e legislativas relativas às temáticas indígenas, iniciativas de desenvolvimento e extração de recursos naturais, dentre outros (NACIONES UNIDAS, 2009). Em seu artigo 6, a Convenção 169 dispõe que, na aplicação das disposições, os governos deverão:

"b) criar meios pelos quais esses povos possam participar livremente, ou pelo menos na mesma medida assegurada aos demais cidadãos, em todos os níveis decisórios de instituições eletivas ou órgãos administrativos responsáveis por políticas e programas que lhes afetem" (ORGANIZAÇÃO INTERNACIONAL DO TRABALHO, 2011, p. 18-19).

${ }^{16}$ Os protocolos de consulta autônomos têm sido formulados por alguns povos e comunidades tradicionais como um instrumento a fim de assegurar seu direito de ser consultado mediante "procedimentos apropriados" e por meio de suas "instituições representativas", conforme determina a Convenção 169 da OIT. Nele encontram-se descritas as regras mínimas e fundamentais para que a consulta seja conduzida de forma adequada pelo Estado, bem como suas formas de organização e de decisão coletiva (GLASS, 2019). 


\section{A PRÁTICA DA CONSULTA E A CONSULTA NA PRÁTICA: REUNIÕES INFORMATIVAS}

No caso do Brasil, o primeiro passo, antes de ser dado início ao trabalho de campo que subsidiará a elaboração do ECQ, deve ser o de consulta junto às comunidades afetadas, por meio de reunião agendada previamente, na qual o empreendedor, acompanhado da empresa de consultoria ambiental contratada por ele, fará uma apresentação do empreendimento e das etapas de elaboração do ECQ, apresentando também os consultores que serão responsáveis pelos estudos, caso recebam a autorização dos quilombolas. Este rito de consulta só é legalmente válido se contar com a participação da Fundação Cultural Palmares ${ }^{17}$. A este órgão cabia a função de

mediar a relação entre empreendedor e comunidade quilombola, responsabilizando-se por garantir e proteger os direitos dessa última, defendendo também seus interesses e prestando assistência técnica e jurídica quando conflitos e impasses se estabelecem com as empresas (BRASIL, 2001).

A interação entre empreendedor, técnicos da Fundação Cultural Palmares e empresa de consultoria é relativamente constante no período que antecede esta, que deve ser a primeira reunião, para que seja possível ajustar cronogramas, estabelecer diretrizes e oferecer orientações com relação ao procedimento de consulta, caso necessário, dentre outros assuntos. Para conferir maior agilidade ao processo, foi acordado entre empresa e Fundação Cultural Palmares que a reunião informativa do parque eólico seria feita conjuntamente com a da linha de transmissão, já que, como vimos, se trata do mesmo empreendedor.

A primeira reunião ocorreu na zona urbana, o que não teve implicações no número de participantes do quilombo Paiol Urbano, já que apenas uma de suas lideranças, e presidente da associação, estava presente. Do quilombo Paiol

\footnotetext{
17 Isto merece ser dito, pois não raro estudos apontam que as empresas responsáveis por estes empreendimentos têm conferido às reuniões que realizam de forma privativa com os quilombolas e/ou audiências públicas o estatuto de consulta.
} 
Rural estavam presentes apenas três pessoas, um casal de idade mais avançada e o irmão da esposa, que se mostraram interessados com a chegada do empreendimento, fato do qual já tinham conhecimento em virtude da circulação de pessoas, dos boatos na cidade e do arrendamento de uma área situada na comunidade vizinha para instalação de um aerogerador. Além desses poucos membros dos quilombos Paiol Urbano e Paiol Rural, estavam presentes os técnicos designados para representar cada um dos empreendimentos, técnicos das duas empresas de consultoria ambienta ${ }^{18}$ e o representante da Fundação Cultural Palmares.

Em linhas gerais, o formato que estas reuniões assumem não costuma variar muito. A liderança comunitária costuma fazer a abertura da reunião, seguida do representante da Fundação Cultural Palmares, que, valendo-se de uma linguagem de fácil entendimento, explica sobre a atuação do órgão, enfatizando quais são suas atribuições junto aos quilombos brasileiros, bem como as razões que justificam sua presença ali. Discorre também sobre a base legal do processo de licenciamento e sobre os direitos adquiridos pelas comunidades quilombolas de serem consultadas quando seus territórios estiverem situados na área de influência direta de um empreendimento. Depois disso, é a vez do empreendedor apresentar o projeto em tela, utilizando com frequência dados técnicos para tal fim. Finalizada sua apresentação, passa-se, então, a palavra para o técnico da consultoria ambiental, que irá explanar sobre a natureza de um ECQ, seus objetivos e a maneira pela qual será conduzido o trabalho de campo para, depois, os quilombolas serem consultados sobre sua permissão para iniciarem os estudos específicos.

Antes de iniciar a reunião, e enquanto o técnico da Fundação Cultural Palmares organizava seus pertences e conversava com algumas pessoas ao seu redor, chamou a atenção uma pequena roda composta pelos poucos afetados presentes em torno do representante do empreendimento eólico, que enaltecia, sob ouvidos atentos, as vantagens de uma obra deste porte em termos

\footnotetext{
${ }_{18}$ O empreendedor optou por contratar empresas distintas para prestarem serviço de consultoria. Uma delas ficou encarregada da elaboração do ECQ e PBAQ associados ao parque eólico e a outra dos mesmos estudos associados à linha de transmissão.
} 
sociais e ambientais. No que concerne à questão ambiental, os parques eólicos contribuiriam para a preservação do meio ambiente, uma vez que, segundo a explicação que concedeu, o cercamento da área onde são instalados os aerogeradores e a restrição à determinadas atividades econômicas em seu interior e entorno assegurariam a reprodução de determinadas espécies. Para corroborar suas afirmações, citou como exemplo outro parque eólico de propriedade da empresa que já estava em operação e teria contribuído para o aumento dos indivíduos de uma espécie de mamífero que se encontrava em risco de extinção, mas que, depois de construído o parque, voltou a ser avistada ${ }^{19}$. Em termos sociais, a vantagem estaria relacionada ao desenvolvimento econômico do município e à geração de empregos. Outra vantagem elencada pelo representante da empresa se referia à beleza cênica dos parques eólicos, citando casos situados em outros países em que eles são objeto de interesse turístico. Os quilombolas presentes concordaram com suas afirmações e um dos residentes do quilombo Paiol Rural fez menção à instalação de um aerogerador da empresa na pequena propriedade de um morador da comunidade vizinha ao quilombo, que, para tanto, estava recebendo um "aluguel".

Durante sua apresentação do parque eólico, agora a todos os presentes, ele voltou a destacar os benefícios, utilizando exemplos retirados de outras localidades nas quais a empresa já possuía estas instalações em operação. $\mathrm{O}$ que chama a atenção nos "projetos sociais", conforme os classificou, elencados por ele, que estariam voltados às comunidades afetadas, é sua variedade temática e o fato de alguns deles preverem ações que seriam responsabilidade do Estado fornecer de forma gratuita. É o caso, por exemplo, do acesso à água por meio de instalação de cisternas e do "Programa Sorriso no Campo", que oferece à população do município afetado atendimento odontológico por meio de uma unidade móvel. Os outros "projetos" aos quais se referiu foram: oficinas de capacitação, cursos profissionalizantes, regulamentação ambiental (CAR), georreferenciamento, averbação da reserva legal e prevenção de abuso sexual.

\footnotetext{
19 Nota-se que a relação de causalidade construída pelo técnico da empresa desconsidera elementos outros que poderiam estar associados ao aumento do número de indivíduos desta espécie, que teria sido observado, atribuindo exclusivamente, e aparentemente sem base em pesquisas científicas, este feito ao parque eólico.
} 
Durante esta apresentação, o representante da Fundação Cultural Palmares pede mais de uma vez a palavra e enfatiza que as referidas ações por parte da empresa empreendedora correspondiam aos direitos das comunidades afetadas e que não se tratava de favores ou atos de generosidade por parte dela.

Passada a palavra para outro técnico da empresa, agora representando a linha de transmissão, inicia-se a apresentação dos dados técnicos do empreendimento e sua contribuição em termos do aumento da oferta de eletricidade no país e no Nordeste. A fala de ambos os representantes da empresa aponta para uma tentativa de mostrar aos presentes as vantagens que podem estar associadas à sua condição de afetados, buscando transformá-la em algo atraente ao apresentá-la como uma espécie de atalho na busca por acesso a certos recursos e direitos (educacionais, sociais, profissionais, de infraestrutura).

Concluída a exposição sobre os dois empreendimentos, os técnicos das duas consultorias ambientais contratadas para cada um deles apresentaram as características e os objetivos de um ECQ, que, caso os quilombolas presentes autorizassem, seria realizado por eles.

Após este conjunto de apresentações, o técnico da Fundação Cultural Palmares consulta os poucos membros das duas comunidades sobre seu consentimento para que fossem iniciados os estudos específicos de cada um dos empreendimentos e dos quais recebe resposta afirmativa, sem maiores questionamentos ou pedidos de esclarecimentos de dúvidas.

Diferente do que se observou na reunião informativa dos quilombos Paiol Urbano e Paiol Rural, a de Mumbuca contou com um grande número de participantes, dentre os quais dois representantes de organizações da sociedade civil que trabalham em prol dos direitos dos quilombolas, que haviam sido convidados pela liderança da comunidade. Se comparada à reunião anterior, chamou também a atenção o número de perguntas, intervenções e pedidos de esclarecimento feitos tanto pelos representantes quanto pelos quilombolas, os quais - estes últimos -, desde o início, se mostraram receosos e se definiram como inseguros em relação ao empreendimento e a seus possíveis impactos.

A apresentação do técnico da Fundação Cultural Palmares seguiu o mesmo formato do dia anterior e, novamente, foi enfatizado por ele o 
significado e a importância daquela reunião para as comunidades quilombolas, historicamente excluídas destes processos, mas que, agora, conquistaram o direito de serem consultadas. Em virtude daquele direito, explicou, a comunidade estava sendo consultada sobre sua permissão para a realização do ECQ. Citou ainda os recursos disponíveis às comunidades quilombolas caso se sentissem prejudicadas ou os processos não fossem conduzidos de acordo com o que exigem as normativas.

Diante do comportamento e das manifestações de receio e resistência dos presentes, o técnico da Fundação Cultural Palmares esclareceu, por mais de uma vez, que o pedido de permissão que estava sendo feito naquele momento não se referia à instalação do empreendimento, mas à realização do ECQ. Diante do questionamento da representante da articulação estadual das comunidades quilombolas, que indagou se a comunidade deveria justificar sua recusa em aceitar a elaboração do ECQ, ele explanou que tal decisão é plausível, mas deve ser discutida pela comunidade, contudo ponderou que tais estudos são instrumentos importantes para conhecer melhor o empreendimento e seus possíveis impactos.

O técnico esclareceu ainda que, embora não seja um relatório técnico de identificação e delimitação (RTID), se trata de um "documento importante" para a comunidade, na medida em que condensa uma série de informações relevantes sobre eles. Esse "raio X" da comunidade, conforme ele classificou, poderia ser utilizado futuramente pela própria Fundação Cultural Palmares para "pleitear políticas públicas", além de traçar um polígono do território (elaborado a partir de informações fornecidas pelos quilombolas) que, futuramente, poderia ser utilizado como subsídio no momento de elaboração do RTID do quilombo ${ }^{20}$.

O representante da Fundação Cultural Palmares, diante dos receios apresentados pelos quilombolas e da possibilidade de recusa do estudo, buscou ponderar os posicionamentos apresentados, dirimir inconsistências e explicitar

\footnotetext{
${ }^{20}$ Nos casos das comunidades que ainda não possuem o RTID, são os ECQ que fornecerão alguns dados sobre suas fronteiras territoriais e traçarão o desenho de um polígono do território para que seja possível estabelecer as distâncias em relação ao empreendimento e, assim, levantar os possíveis impactos.
} 
as regras implícitas desse jogo. Em primeiro lugar, esclareceu que a participação de grupos e atores no processo de licenciamento ambiental possui uma natureza consultiva, e não deliberativa, ou seja, uma eventual recusa na elaboração dos estudos ou oposição em relação à implantação da linha de transmissão deveriam ser fundamentadas tecnicamente e, ainda assim, não significavam um veto ao empreendimento. Informou ainda que os casos empíricos que a Fundação Cultural Palmares tem acompanhado permitem sugerir que boa parte dos empreendimentos são licenciados, a despeito da resistência apresentada pelas comunidades e dos questionamentos dos órgãos públicos envolvidos no processo, dentre os quais a própria Fundação. Com isso, tentou deixar claro aos presentes as assimetrias de poder que acompanham um processo de licenciamento ambiental e o não cumprimento de sua prerrogativa, que é consultar e, se necessário, vetar o empreendimento ${ }^{21}$.

Embora esta informação tenha sido importante naquele contexto em que a comunidade tomava contato pela primeira vez com um processo de licenciamento ambiental, isto não é uma novidade entre aqueles que pesquisam este tema. Zhouri (2008) e Zhouri, Laschefski e Paiva (2005), por exemplo, já haviam apontado para as posições hierarquizadas e as desigualdades nas relações de poder que permeiam o campo ambiental brasileiro, bem como para as características do que chamam de paradigma da adequação ambiental, no interior do qual se dariam os processos de licenciamento ambiental. Para os autores, o licenciamento, na forma como vem sendo praticado no Brasil, não cumpre sua função de instrumento de avaliação da sustentabilidade socioambiental dos empreendimentos; ao contrário, viabiliza unicamente a apropriação capitalista dos recursos naturais.

A fala do agente governamental aponta também para o caráter inexorável destes empreendimentos, condição que já foi sublinhada anteriormente em outros estudos que se debruçaram sobre o licenciamento ambiental de grandes obras. Zhouri et al. (2018) chamaram a atenção para

\footnotetext{
${ }^{21}$ A Resolução Conama nº 1/1986 estabelece que o estudo de impacto ambiental deve "contemplar todas as alternativas tecnológicas e de localização do projeto, confrontando-as com a hipótese de não execução do projeto".
} 
a inexorabilidade da ideologia do desenvolvimento que se observa nestes contextos e que, dentre outras coisas, produz flexibilização nas regras que disciplinam o licenciamento e a precarização das condições de trabalho dos técnicos governamentais que atuam nos órgãos encarregados de acompanhar e se manifestar sobre estes processos.

Depois de discorrer brevemente sobre esta empiria, o técnico da Fundação Cultural Palmares sugere, então, que o mais prudente talvez não fosse a recusa imediata dos estudos, uma vez que serão eles que permitirão identificar os impactos do empreendimento e avaliar sua magnitude, ao mesmo tempo que subsidiariam o parecer da entidade junto ao órgão licenciador. Explicou ainda que uma eventual recusa da comunidade ou manifestação contrária da Fundação Cultural Palmares com relação ao empreendimento devem vir acompanhadas de argumentos e informações técnicas que justifiquem tal posicionamento, deixando evidente a primazia do idioma técnico-científico nos processos decisórios e nas interações com o Estado ${ }^{22}$. Ao lado do levantamento de dados sobre a comunidade, essa foi mais uma das razões apresentadas por ele para defender a importância de um estudo desta natureza.

A reunião prossegue e, depois de encerradas as apresentações dos outros atores (empreendedor e empresa de consultoria ambiental) e esclarecidas as dúvidas dos presentes, a comunidade quilombola, por meio de sua presidente, comunica sua decisão: iriam se reunir na semana seguinte para discutirem melhor e decidirem sobre sua permissão ou recusa em aceitar a elaboração do ECQ, comprometendo-se a informar o técnico governamental responsável tão logo tomassem essa decisão. Dentro do prazo acordado, a presidente da associação quilombola comunicou a decisão da comunidade à Fundação Cultural Palmares autorizando a realização dos estudos que, duas semanas depois, se iniciaram.

\footnotetext{
${ }^{22}$ Disso decorre a necessidade que se observa nestes contextos de profissionais especializados cujo papel consiste em traduzir as percepções e avaliações nativas para uma linguagem que esteja amparada na técnica e na ciência.
} 


\section{O TRABALHO DE CAMPO PARA ELABORAÇÃO DO ESTUDO DO COMPONENTE QUILOMBOLA}

Apesar das inúmeras semelhanças que marcaram o trabalho de campo nas duas comunidades - e que serão descritas adiante - chamou a atenção o contraste na forma como ambas representavam o empreendimento.

Embora no decorrer da pesquisa tenha se dissipado a desconfiança que os moradores do quilombo Mumbuca nutriam também em relação aos consultores, a resistência ao empreendimento se manteve. Os quilombolas desde o início alegavam com frequência receio e medo ante os impactos que o empreendimento poderia causar em suas dinâmicas sociais e territoriais e mesmo em sua reivindicação recente pelo território. Este sentimento, presente antes de serem identificados os impactos, se manteve depois que eles foram levantados pela equipe de consultores em parceria com os quilombolas. Um deles estava relacionado ao fato de as torres serem projetadas para instalação numa área que se encontra sob o poder de um fazendeiro, mas onde as famílias quilombolas exercem historicamente a posse por meio de atividades agrícolas, extrativas e pastoris. Trata-se de um local considerado por eles como pertencente ao território historicamente ocupado ${ }^{23}$, que foi largamente utilizado pelas gerações precedentes para desenvolveram atividades agrícolas, pastoris e extrativas. Durante muitos anos essas atividades foram realizadas no regime de $\operatorname{meia}^{24}$, mas recentemente o fazendeiro as restringiu, embora outras continuem sendo praticadas ${ }^{25}$, a despeito dos conflitos

\footnotetext{
${ }^{23}$ O quilombo Mumbuca se formou no interior de uma antiga e extensa fazenda de gado do século XVIII para a qual seus antepassados trabalhavam e na qual residiam. A extensão da área atualmente reivindicada corresponde a uma parcela das terras desta fazenda e costuma ser dividida pelos moradores entre território ocupado e território histórico. O primeiro corresponde à área de moradia e local onde estão as terras de herdeiro (Cf. ALMEIDA, 1989), enquanto o segundo faz referência às terras que estão nas mãos de terceiros, mas onde eles permanecem exercendo a posse por meio de atividades agrícolas, pastoris e extrativas, como é o caso daquela em que estava projetada a instalação das torres.

${ }^{24}$ O regime de meia consiste em conceder uma parcela da produção agrícola ao proprietário do terreno onde se desenvolve esta atividade.

${ }^{25}$ As famílias quilombolas utilizam esta área para coleta de frutas nativas e pastoreio de seus animais, que convivem no mesmo espaço com aqueles pertencentes ao suposto proprietário do terreno.
} 
recorrentes ${ }^{26}$. Esta área continua sendo de grande interesse para os quilombolas, por suas terras serem consideradas férteis para o cultivo e produtivas para o extrativismo e a criação de animais, além de contar com um açude de médio porte que utilizam para pescar e de onde retiravam água até a instalação das cisternas.

Em função disso, permaneceram qualificando o projeto de instalação da linha de transmissão como uma ameaça. De acordo com a presidente da associação, "a empresa é uma ameaça porque está matando nossa história, nossa fonte de vida. Para a gente é uma ameaça porque a gente sobrevive dali". Observou-se entre estes moradores certo consenso em relação ao empreendimento e os impactos negativos que ele causaria, o que resultou numa forte pressão sobre o empreendedor, que será descrita no tópico seguinte.

Os quilombolas de Paiol Rural, ao contrário, desde o início deixaram evidente seu dissenso em relação ao projeto de instalação da linha de transmissão. Durante os primeiros dias de trabalho de campo, observou-se o pequeno interesse dos moradores em participar do processo de levantamento dos dados que iriam compor o ECQ, com exceção de algumas famílias. Essa divergência pode, em parte, ser explicada pela distribuição diferencial da propriedade da terra entre as famílias do quilombo, no interior do território de ocupação tradicional quilombola ${ }^{27}$, e do aporte financeiro oportunizado pelo empreendimento por meio do arrendamento das terras para instalação das torres, assim como dos aerogeradores do parque eólico.

Alguns fatores que antecederam a chegada destes dois empreendimentos contribuíram para gerar uma expectativa favorável de algumas famílias em torno deles. Um deles se refere à experiência de um morador da comunidade vizinha (que não era quilombola), que arrendou sua propriedade para a instalação dos aerogeradores do parque eólico, da qual tomaram conhecimento em virtude da amizade que mantinham com ele e das notícias que

\footnotetext{
${ }^{26}$ O quilombo Mumbuca foi certificado em 2018 e ainda não possui um RTID, o que contribui para a ocorrência de conflitos com supostos proprietários de terras cujas áreas incidem sobre o território que pretendem reivindicar.

27 Certificado em 2004, e ainda sem RTID, este quilombo é composto por seis sítios, titulados, cuja maioria se configura atualmente como terra de herdeiro.
} 
circulavam na cidade. Em alguns momentos chegaram também a destacar a beleza que viam nos parques eólicos, que estava relacionada à sua magnitude e luminosidade à noite.

Outro fator que teria favorecido a imagem positiva em torno destes dois projetos está relacionado a duas experiências de arrendamento de parcelas de suas terras a empresas ${ }^{28}$. Uma delas, mais atual, para a instalação de torres de medição de ventos, e a outra, mais antiga, para uma pequena mineradora de mármore que teria se instalado no local na década de 1990, quando ainda não haviam sido reconhecidos como quilombolas. Durante o período em que esteve em atividade, a mineradora teria gerado inúmeros empregos para os moradores e também uma renda para a família proprietária da área arrendada.

Segundo a presidente da associação, por uma coincidência, a mineradora veio à falência justamente no ano em que foram reconhecidos enquanto comunidade quilombola. Durante o trabalho de campo para elaboração do $\mathrm{ECQ}$, as causas de sua falência permaneciam desconhecidas para os moradores, que passaram a associá-la ao fato de terem sido certificados como comunidade quilombola, o que, em sua interpretação, teria acarretado o impedimento de seu funcionamento no interior do território recém-reconhecido. Esse acontecimento pode ter resultado numa percepção negativa sobre o reconhecimento, sobretudo por parte de algumas famílias, que passaram a associá-lo à escassez de trabalho e renda na comunidade.

O mesmo raciocínio foi empregado quando constataram que, diferente do que ocorreu com a comunidade vizinha, eles não foram procurados pela empresa com o interesse em arrendar suas terras. Esta comparação foi suficiente para confirmarem uma suspeita que já vinha sendo nutrida desde a paralisação das atividades da mineradora, qual seja, a de que o reconhecimento de seu pertencimento étnico impedia que determinadas atividades econômicas fossem desenvolvidas no território quilombola. Ainda assim, os quilombolas de Paiol Rural aguardavam com grande expectativa o cruzamento dos dados

\footnotetext{
${ }_{28}$ A prática de concessão temporária de parcelas de terra mediante pagamento não é incomum neste quilombo. Para além dos atores externos, os moradores costumam se valer entre si do que denominam como "contrato de comodato", que consiste na concessão de uma área (no interior de sua terra de herdeiro) a outro morador que não a possui ou necessita de mais extensões de terra para desenvolver suas atividades produtivas.
} 
cartográficos que viria a confirmar (ou não) a incidência das torres no território e precisar sua localização, ou seja, em quais dos seis sítios que compõem o território estariam inseridas. Os moradores de Mumbuca, ao contrário, em nenhum momento manifestaram qualquer expectativa em arrendar as terras de sua propriedade.

As circunstâncias, sobretudo econômicas, em que se encontravam as duas comunidades no momento da consulta nos fornecem algumas pistas para compreender seu posicionamento divergente diante do empreendimento. Apesar da vasta extensão do território quilombola de Paiol Rural, a maioria das famílias migrou para a zona urbana do município, ou para outros estados, em virtude das poucas alternativas econômicas disponíveis no local e da ausência e/ou inatividade de equipamentos de infraestrutura, como escola, posto de saúde e transporte ${ }^{29}$. Aqueles que permaneceram se dedicam ao trabalho familiar na agricultura e na pecuária, com raros incentivos governamentais e não governamentais. Alguns dos moradores que se deslocaram para o quilombo Paiol Urbano, apesar de constituírem residência na cidade, permaneceram cultivando suas terras no quilombo rural, a despeito das dificuldades.

O quilombo Mumbuca, por sua vez, é composto por poucas (e diminutas) terras de herdeiro - onde se encontram a maior parte das moradias - e as famílias exercem a posse no restante do território que reivindicam como quilombola. Assim como em Paiol Rural, o regime de apropriação do espaço se apoia na unidade de trabalho familiar voltada para a agricultura, criação de animais e uso comum de determinados recursos naturais ${ }^{30}$. Desde sua certificação como quilombola, em 2018, a comunidade passou a ser assistida por uma série de projetos governamentais (estaduais) e não governamentais ${ }^{31}$, o que teria, segundo seus moradores, dinamizado significativamente a economia local, fortalecendo as atividades

${ }^{29}$ O quilombo localiza-se numa área de difícil acesso, distante uma hora da zona urbana, que nos períodos de chuva intensa costuma ficar interditada. Esta dificuldade no acesso é utilizada pelos governantes municipais para justificar o não atendimento da comunidade por transporte público escolar e ambulâncias, por exemplo.

30 Se configurando no que Almeida $(2008,2010)$ designa como "terras tradicionalmente ocupadas".

${ }^{31}$ Dentre os quais podemos citar a construção de diferentes modalidades de cisternas (pluvial, enxurrada, calçadão), barreiros-trincheira, poços artesianos, criação de um banco de sementes crioulas, doação de animais de criação (ovinos e caprinos), concessão de bolsas para os jovens que se dedicam à agricultura e fornecimento de mudas e sementes. 
produtivas comumente praticadas e garantindo sua permanência no território. Soma-se a isso outros elementos que o colocam numa condição mais favorável em comparação com o Paiol Rural, como o fato de contarem com uma escola em atividade, transporte público e proximidade da zona urbana.

Seja qual for a representação que se forjou sobre o empreendimento, o trabalho de campo para elaboração do ECQ revelou que a percepção inicial das duas comunidades sobre eles foi forjada num contexto de quase completa ausência de informações sobre suas características e possíveis impactos. Até o momento da reunião consultiva, o que há disponível para estas comunidades sobre o projeto do empreendimento são informações dispersas, imprecisas e sem consistência. Estamos nos referindo aos boatos que correm na cidade, à constatação de pessoas "de fora" circulando na zona rural e urbana, a presença de estacas, placas e outros marcos espaciais no interior de seus territórios e nas suas proximidades, visitas de técnicos para levantamento fundiário e de dados socioespaciais, dentre outros elementos.

Estas ações por parte da empresa costumam ser levadas a cabo sem que as comunidades tenham sido informadas e a despeito das normativas que determinam que qualquer medida referente ao empreendimento no interior do território quilombola deve aguardar a manifestação da Fundação Cultural Palmares, o que aponta para o não cumprimento da exigência de que a consulta seja prévia e informada ${ }^{32}$. Outro fator é que o contato com membros da comunidade ocorre mesmo antes do rito da consulta, que se inicia com a primeira reunião informativa. No quilombo Paiol Rural foi constatado um incidente desta natureza. Em trabalho de campo, uma moradora e sua filha, em conversa com os consultores que acabavam de informá-las sobre o projeto de construção da linha de transmissão, perguntaram se eles tinham alguma relação com um contrato que a mãe havia assinado meses antes, mas que não sabiam explicar com quem foi celebrado e nem qual era sua finalidade.

\footnotetext{
32 São muitos os casos registrados pela literatura (ALMEIDA et al., 2010, 2019; BESER; CARVALHO, 2019; GLASS, 2019; ROSSITO et al., 2019; SILVA, 2016) que apontam que estes requisitos não são cumpridos. Em alguns contextos, a consulta sequer ocorre, ou vai ocorrer anos depois de instalado o empreendimento e por meio de medidas judiciais, chegando a se configurar como um drama social, conforme o classificaram Beser e Carvalho (2019) em seu estudo sobre consulta aos quilombolas de Oriximiná.
} 
Com a foto em seu celular, sua filha mostra aos técnicos o contrato que a mãe assinou com a empresa empreendedora dispondo 0,075 hectare de suas terras e onde, como viriam a saber por meio dos consultores, seria instalada uma das torres.

Ou seja, muitas vezes é na reunião consultiva/ informativa e durante o trabalho de campo para elaboração do ECQ que a comunidade consegue estabelecer relação entre os boatos, os marcadores espaciais que encontrava em seu território, as pessoas externas que circulavam pelo local e o empreendimento que está sendo apresentado. Este desconhecimento não se apresenta apenas no que concerne ao projeto do empreendimento, mas também aos direitos das comunidades quilombolas num processo de licenciamento ambiental. No caso em questão, trata-se de dois quilombos que nunca antes haviam tido contato com qualquer obra ou atividade deste porte e nada conheciam sobre seus direitos ${ }^{33}$.

Na reunião informativa, o volume de informações disponibilizadas num curto espaço de tempo para pessoas que nunca protagonizaram um processo de licenciamento ambiental faz com que poucas delas sejam de fato retidas e compreendidas $^{34}$. Apesar do esforço do técnico da Fundação Cultural Palmares e dos consultores em tentar explicar a base legal deste processo e os direitos das comunidades quilombolas de serem consultadas e compensadas, nos casos em que forem identificados impactos, trata-se de um modus operandi forjado pelo Estado com o qual muitas destas comunidades não estão habituadas, mas com o qual devem se familiarizar rapidamente para que a natureza participativa da consulta, mesmo que precariamente, seja assegurada ${ }^{35}$.

\footnotetext{
${ }^{33}$ Escassos também eram seus conhecimentos sobre outros direitos dos quais são portadores enquanto grupo étnico e que não estão diretamente associados à temática do licenciamento, como é o caso dos benefícios concedidos a estes grupos por meio de políticas públicas diferenciadas. Em Paiol Rural, por exemplo, com exceção da presidente da associação, nenhum dos interlocutores da pesquisa de campo tinha conhecimento de que poderiam ser, ou que já estavam sendo, beneficiário destas políticas.

34 Outros estudos (ALMEIDA et al., 2013, 2010; BESER; CARVALHO, 2018; ROJAS GARZÓN; YAMADA; OLIVEIRA, 2016; ROSSINI et al., 2019) também chamaram a atenção para as inúmeras dificuldades que envolvem um processo de consulta, como tempo escasso, informações insuficientes, linguagem de difícil acesso, ausência de apoio técnico, pressão para assinatura de documentos, dentre outros.

35 Isso nos remete ao que Almeida et al. (2013), acerca das audiências públicas, classificou como a "ilusão da participação". Ainda a respeito da "participação" em processos de licenciamento ambiental numa perspectiva crítica, ver Bronz (2009).
} 
Não estamos nos referindo apenas à linguagem técnica das áreas de conhecimento envolvidas nesse processo - como o direito, a engenharia ou as ciências sociais -, mas também ao próprio mecanismo de consulta a estas populações que se supõe "livre, prévio e informado", como determina a Convenção 169 da OIT e as normativas da Fundação Cultural Palmares. É inegável a importância deste direito a grupos historicamente excluídos dos processos decisórios sobre medidas que os atingiram e os atingem, no entanto esse direito, ao ser aplicado, esbarra em questões estruturais da sociedade brasileira, como, por exemplo, o desconhecimento acerca dos direitos, a marginalização dos grupos minoritários, a interpretação particularizada das normas e a inexorabilidade da ideologia do desenvolvimento.

As inúmeras precariedades que caracterizam algumas consultas não significam, no entanto, que os quilombolas adotam uma posição passiva e conformada frente a elas. Conforme veremos a seguir, procuram de inúmeras formas - que passam pelo contato com consultores, com a Fundação Cultural Palmares, com organizações da sociedade civil, articulação interna, dentre outras - suprir esse déficit.

\section{A REUNIÃO DEVOLUTIVA: CONSULTA SOBRE O ESTUDO DO COMPONENTE QUILOMBOLA E PLANO BÁSICO AMBIENTAL QUILOMBOLA}

Depois que o ECQ é elaborado pelos técnicos da empresa de consultoria ambiental, ele passa pela avaliação do empreendedor, que tece suas considerações, podendo sugerir mudanças, acréscimos e/ou exclusões. Após esta avaliação, são encaminhados para a Fundação Cultural Palmares, que, por meio do técnico designado para acompanhar o processo, emite seu parecer, aprovando (ou não) os estudos. No caso de aprovação, o empreendedor deve encaminhar com antecedência alguns exemplares para as comunidades, para que sejam previamente informadas sobre a reunião, na qual serão novamente consultadas sobre seu consentimento em relação ao ECQ que está sendo apresentado e ao prosseguimento do processo. 
Via de regra, a apresentação do ECQ antecede a do PBAQ. Isto porque no primeiro consta tanto a caracterização da comunidade quanto o levantamento dos impactos que podem ser causados pelo empreendimento. Nele também constam algumas ações, elencadas de forma genérica e pouco sistematizada, para controlá-los, mitigá-los e/ou compensá-los. Cabe, portanto, ao PBAQ detalhar e organizar em programas específicos as medidas compensatórias que foram levantadas no ECQ e levadas para discussão junto à comunidade no momento de sua apresentação. Depois de pronto (e passando pelas mesmas etapas pelas quais passou o ECQ), é organizada uma nova reunião, agora para consultar as comunidades afetadas sobre sua aprovação do PBAQ.

Apesar desta ser a prática recorrente, no caso em questão, ECQ e PBAQ foram aprovados na mesma reunião, sob a alegação de que a competência para acompanhar os licenciamentos que envolviam comunidades quilombolas seria transferida, em breve, da Fundação Cultural Palmares para o Ministério da Agricultura e Agropecuária (Mapa) ${ }^{36}$, o que impunha a necessidade da entidade finalizar até o final daquele ano os inúmeros processos que se encontravam em andamento. Por este motivo, a aprovação do segundo se deu apenas com base nas medidas sugeridas no ECQ, uma vez que ele ainda não havia sido elaborado até o momento em que foi realizada a reunião. Depois de pronto, foi encaminhado à Fundação Cultural Palmares e, a critério do técnico, prescindiu de uma nova consulta às comunidades, uma vez que já havia sido aprovado na reunião de apresentação do ECQ.

Para ambas as comunidades, foram identificados impactos decorrentes da instalação e operação da linha de transmissão e propostas medidas para que pudessem ser devidamente compensadas.

A apresentação do ECQ às comunidades foi feita pelos consultores que o elaboraram e, conforme exigem as normativas que disciplinam o processo, estavam presentes na reunião um representante da Fundação Cultural Palmares e um técnico da empresa responsável pelo empreendimento, o mesmo

\footnotetext{
${ }^{36}$ Medida prevista no decreto $n^{\circ} 9.667$, de 2 de janeiro de 2019, e atualizada na definição de estrutura regimental e o quadro demonstrativo dos cargos em comissão e das funções de confiança do Incra (Decreto $\mathrm{n}^{\circ} 10.252$, de 20 de fevereiro de 2020, artigo 13, Inciso VII).
} 
que compareceu à reunião informativa e que acompanhou todo o processo. Já com relação à Fundação Cultural Palmares, em virtude das mudanças pelas quais estava passando o órgão, que acarretaram exonerações e afastamentos de alguns de seus membros, houve substituição, no período em que se realizava o trabalho de campo, do técnico até então encarregado de acompanhar o processo. O novo responsável, por ter sido alocado nesta função posteriormente, participou apenas da avaliação do ECQ e PBAQ e das reuniões devolutivas.

Neste momento, novamente, as duas comunidades consultadas trilham caminhos distintos, a despeito dos impactos identificados terem sido praticamente os mesmos para as duas, bem como as medidas propostas para lidar com eles. Estamos nos referindo à diferença no tratamento que cada comunidade recebeu por parte do empreendedor, o que se explica, como buscaremos demonstrar, pela capacidade de negociar e de exercer pressão de suas lideranças, bem como por seu contato prévio com movimentos sociais e organizações da sociedade civil que atuam em prol dos direitos quilombolas. Esse atributo teve influência significativa no que diz respeito ao direito destas comunidades de serem devidamente compensadas pelos impactos causados pelo empreendimento. Vejamos em mais detalhes como isso se deu.

Diferentemente do que se observou na primeira reunião de consulta (reunião informativa), havia um número significativo de moradores na reunião que ocorreu no quilombo Paiol Rural para consultá-los sobre seu consentimento em relação ao ECQ, ao PBAQ e, consequentemente, ao prosseguimento do processo de licenciamento ambiental da obra. Muitos daqueles que se mostraram interessados quando se iniciaram os trabalhos não compareceram à reunião, talvez em virtude de estarem cientes de que as torres incidiriam sobre as terras de outras famílias. Além do maior número de presentes, observou-se também maior participação e interesse dos quilombolas em conhecer as implicações do empreendimento e as ações para compensá-los pelos impactos.

Ainda que pedidos de esclarecimento e dúvidas tenham sido apresentados por eles durante a reunião, não houve questionamentos acerca das medidas esboçadas no ECQ, como sugestões de alterações ou pedidos para incluir medidas mitigadoras e/ou compensatórias que não estavam presentes no 
estudo, mas que haviam sido apresentadas pela comunidade no curso do trabalho de campo. Esse consentimento em relação ao que estava sendo proposto como compensação ${ }^{37}$ parece estar menos associado a uma concordância plena com relação às ações propostas e mais a uma ausência de mobilização destes moradores enquanto grupo capaz de exercer pressão sobre o empreendedor.

O quilombo Mumbuca, ao contrário, mesmo com as ações propostas no ECQ, se empenhou em organizar suas demandas para apresentá-las ao empreendedor naquele momento de consulta. Por meio de sua liderança, que também era presidente da associação, foram sugeridos acréscimos e alterações, pois não se consideravam justamente compensados. A presidente da associação, por mais de uma vez, reforçou a importância das terras onde incidiriam as torres para a subsistência das famílias quilombolas e os transtornos que a implementação da linha de transmissão, sobretudo no momento de sua instalação, causaria às atividades comunitárias. Ela questionou o fato de uma das ações que os quilombolas julgavam adequadas para compensá-los (a construção de uma sede para sua associação) não ter sido incluída como uma ação compensatória. Acrescentou ainda a limpeza dos barreiros comunitários (de onde os moradores retiram água) e o fornecimento de ração aos animais de criação, como outras duas medidas que não haviam sido contempladas pelo empreendedor, mesmo tendo sido apontadas como demanda comunitária.

Diante do exposto pela liderança, o representante do empreendimento respondeu que os quilombolas deveriam escolher entre as ações que estavam sendo demandadas, mais precisamente entre a construção da sede e a limpeza do barreiro. De seu ponto de vista, a comunidade estaria excedendo em suas demandas por compensação, haja vista que, como ele próprio afirmou durante a reunião, a área na qual as torres estavam projetadas para serem instaladas, embora reconhecida pelos quilombolas como território historicamente ocupado, se encontrava sob propriedade particular ${ }^{38}$. Expressou ainda o fato de a comunidade não possuir um RTID que lhes assegurasse o domínio

\footnotetext{
37 Construção de um poço artesiano, oficinas e cursos de capacitação diversos (gestão de resíduos, formação de agentes ambientais, associativismo, captação de recursos, cultivo de palma, apoio às atividades agropecuárias) e apoio à organização de atividades culturais.

${ }^{38}$ Esta área corresponde àquela sobre a qual já foi feita referência.
} 
formal sobre a referida parcela de terra como um elemento que os quilombolas deveriam levar em consideração ao fazerem suas demandas.

Ao lançar mão deste argumento, o representante do empreendedor evidencia não apenas seu desconhecimento em relação às normativas da Fundação Cultural Palmares que disciplinam o processo de consulta ${ }^{39}$, mas também deixa explícita sua tentativa de deslegitimar as cosmografias (LITTLE, 2001) dos quilombolas. Mais do que um desconhecimento, trata-se de uma interpretação legalista (e situacional) das normas como uma forma de manter o patamar das negociações nos limites que ali apresentaram.

O técnico da Fundação Cultural Palmares, diante das argumentações do empreendedor e da liderança quilombola, sugere que seja registrada em ata a demanda pela construção da sede para a associação, mas não procede da mesma maneira com relação à limpeza dos barreiros, tampouco com relação ao fornecimento de ração. A reunião foi permeada por intensas tentativas de negociação, entre empreendedor e quilombolas, das medidas que deveriam fazer frente aos impactos causados pelo empreendimento, com pontuais intervenções por parte do técnico governamental, que se concentraram mais em solicitar a inclusão de determinados pontos na ata ${ }^{40}$.

Chamamos a atenção para este fato, pois ele nos remete ao tema da suposta impessoalidade da burocracia. Nota-se que a atuação da Fundação Cultural Palmares ganha contornos diferenciados a depender do técnico que acompanha

\footnotetext{
39 Embora conste na Portaria Interministerial nº 60/2015 que são as comunidades quilombolas que possuem RTID que devem ser contempladas com estudos específicos, nos dias de hoje prevalece a interpretação de que a certificação já confere o direito à consulta, conforme disposto na Instrução Normativa da FCP $n^{\circ} 1 / 2018$ e na Recomendação no $2 / 2016$ das $4^{a}$ e $6^{\mathrm{a}}$ Câmaras de Coordenação e Revisão da Procuradoria Federal dos Direitos do Cidadão, do Ministério Público Federal. Essa reinterpretação se mostra importante diante do fato de que a maioria das comunidades quilombolas no Brasil não possui RTID, o que impediria sua participação nos processos de consulta. A Convenção 169 da OIT, por sua vez, reconhece "o direito de posse e propriedade desses povos [...], inclusive sobre terras que, como observado em determinados casos, não sejam exclusivamente ocupadas por eles, mas às quais tenham, tradicionalmente, tido acesso para suas atividades e subsistência" (ORGANIZAÇÃO INTERNACIONAL DO TRABALHO, 2011, p. 9).

40 Tal postura se diferenciava, em certa medida, daquela adotada pelo técnico que conduziu a primeira reunião de consulta, o qual enfatizou, constantemente, os direitos quilombolas e ressaltou a importância das comunidades exercerem seu direito de serem consultadas e devidamente compensadas quando identificados impactos, bem como apontou os caminhos e as instâncias que podem ser acionados nos casos em que estes direitos não são observados.
} 
o processo ${ }^{41}$. A ausência de protocolos claros que normatizem a atuação dos agentes públicos pode ser considerada como um dos elementos que favorecem sobremaneira esta prática e contribui para o entendimento e aplicação particularizada da norma, como já apontado por Kant de Lima (1995).

Mesmo com a tímida participação do técnico da Fundação Cultural Palmares nesta segunda consulta, chegou-se a um consenso entre as partes, ainda que a comunidade considerasse que a limpeza dos barreiros e o fornecimento de ração para seus animais - e que não foram registrados em ata, como ocorreu com a construção da sede - fossem ações fundamentais para a compensação dos impactos ${ }^{42}$. Ao final desta consulta, os presentes manifestaram sua concordância com relação ao ECQ e as ações nele sugeridas, e foi dado como aprovado tanto ECQ quanto PBAQ.

Os momentos formais de consulta às comunidades afetadas são etapas importantes no que diz respeito ao exercício do direito de serem consultadas e devidamente compensadas. Sua importância também reside no fato das comunidades contarem com a presença do órgão encarregado de fazer valer seus direitos, que nesses casos deve atuar como um mediador a fim de que as assimetrias entre os atores que permeiam este campo sejam, mesmo que parcial e pontualmente, corrigidas. Embora o rito da consulta seja peça-chave no processo, as negociações entre empreendedor e comunidades nem sempre se esgotam nestes momentos e, mais do que isso, nem sempre se dão sob o olhar e a mediação da Fundação Cultural Palmares. O quilombo Mumbuca pode ser tomado como um exemplo neste sentido, pois sua liderança e o representante do empreendimento permaneceram em contato constante no período que sucedeu a reunião devolutiva. Para além do acompanhamento do licenciamento, este diálogo entre eles permitiu que uma das ações que havia sido

${ }^{41}$ Este é um dos motivos pelos quais, entre os representantes dos empreendedores e das empresas de consultoria, circulam comentários acerca das características de cada técnico da Fundação Cultural Palmares que se torna responsável por acompanhar um processo, estando eles voltados a ressaltar sua maior ou menor flexibilidade para negociação com o empreendedor. Ou seja, quanto maior sua flexibilidade, mais interessante do ponto de vista da iniciativa privada que implementa estas obras.

${ }^{42}$ Isso se justifica porque as famílias quilombolas utilizam a área onde serão instaladas as torres para a criação de caprinos, ovinos e bovinos e, eventualmente, para retirar água do açude. No período de instalação, haveria uma interdição temporária para o uso destas áreas em virtude das atividades necessárias para a consolidação das obras. 
pleiteada pela comunidade durante a reunião (a limpeza dos barreiros) fosse, finalmente, aceita.

Esse fato revela o tratamento diferenciado que as duas comunidades receberam por parte do empreendedor no momento final do processo de consulta e suas expectativas de direitos diferenciadas. Como vimos, os quilombolas de Paiol Rural não reclamaram a inclusão no ECQ de algumas medidas que julgavam necessárias e que haviam sido levantadas por eles durante o trabalho de campo dos técnicos. Esse silenciamento durante a reunião de apresentação do ECQ explica o menor número de ações mitigadoras e compensatórias destinadas a essa comunidade em comparação com o quilombo Mumbuca ${ }^{43}$, que, ao contrário, em virtude da pressão que exerceu sobre o empreendedor, teve a maioria de suas demandas por compensação atendida.

Esta conquista por parte dos moradores deste quilombo revela, ainda, que o direito de ser justamente compensado pelos impactos decorrentes de um empreendimento não está completamente assegurado, sendo necessário demonstrar habilidade para negociar as medidas com o empreendedor e, assim, fazer valer os direitos que lhes são assegurados. O conhecimento e esclarecimentos acerca destes direitos, por sua vez, decorreu da interação que a liderança comunitária mantinha com representantes de movimentos sociais e de organizações da sociedade civil que atuam em prol das comunidades quilombolas. Embora não tenham comparecido à reunião devolutiva do quilombo Mumbuca, o contato entre estes atores e a presidente da associação quilombola se manteve frequente ao longo do processo.

\section{CONSIDERAÇõES FINAIS}

A partir da descrição de duas situações etnográficas, procuramos problematizar a maneira como vem se dando o exercício do direito à consulta

\footnotetext{
${ }^{43}$ Além do que foi previsto para Paiol Rural, foram autorizados para o quilombo Mumbuca a construção de uma sede, a limpeza dos barreiros e o fornecimento temporário de caminhões-pipa para o abastecimento de cisternas.
} 
de comunidades quilombolas em processos de licenciamento ambiental. Tais situações revelam aspectos relevantes sobre o funcionamento do Estado, das instituições públicas ou privadas e dos atores envolvidos nesses procedimentos de consulta.

O primeiro ponto a ser destacado diz respeito ao modo como a consulta se constitui em um aparelho político frágil, ao considerarmos que, em muitas circunstâncias, elas são realizadas quando as licenças já foram emitidas e algumas ações para viabilização do empreendimento (como, por exemplo, o arrendamento de terras) já foram iniciadas. Soma-se a isso o fato dos mecanismos de difusão e esclarecimento de informações acerca dos riscos de um empreendimento e mesmo sobre os direitos das comunidades quilombolas num processo de licenciamento não atingirem um número expressivo de pessoas. A desigualdade no tratamento que o empreendedor destina às comunidades que se encontram numa situação muito similar ao longo do processo de consulta provoca, por sua vez, um acesso diferenciado aos direitos de que são portadoras (dentre os quais o de serem devidamente compensadas pelos impactos decorrentes do empreendimento), transformando-os em privilégios.

A atuação (ou não) de mediadores também se mostrou um fator relevante para a compreensão das especificidades que observamos em cada caso, bem como as condições materiais em que se encontra a comunidade no momento de chegada do empreendimento. Como vimos, Mumbuca é assistida por inúmeros projetos fruto de parcerias entre sua associação e entidades governamentais estaduais e organizações da sociedade civil. O fator econômico e o poder de negociação, como já havia alertado Acselrad (2010), é importante para compreender o consentimento (ou não) de atores sociais locais diante de empreendimentos portadores de riscos.

O segundo ponto se refere à dimensão moral e simbólica que a norma ocupa no espaço público brasileiro. Conforme cientistas sociais brasileiros já apontaram (KANT DE LIMA, 1995; OLIVEIRA, 2002), verifica-se, no Brasil, uma significativa desarticulação entre as normas e o plano das interações sociais. Neste universo interacional, a norma é compreendida como um 
instrumento externo aos indivíduos, propriedade particular das instituições do Estado, logo não produz o efeito observado em países capitalistas e democráticos, qual seja, a normalização das condutas. Como observou Kant de Lima (1995), nossa estrutura política e jurídica possui como uma de suas marcas principais a particularização do conhecimento e das regras. A inexistência e a dificuldade de conformação de consensos sobre os fatos e as normas reforça essa dimensão hierárquica, desigual e particularizada do seu exercício. Isso nos permite sugerir que o exercício do direito de ser consultado, no Brasil, é marcado por uma dificuldade de acesso aos sistemas que compõem o Estado e garantem direitos de acesso ao espaço público e às regras.

Ademais, as fragilidades do mecanismo de consulta aos povos e comunidades tradicionais e as assimetrias de poder que perpassam o campo do licenciamento ambiental, descritas neste trabalho, tendem a se acentuar num contexto como o atual, em que se observam as frequentes investidas por parte do governo federal na tentativa de flexibilizar as regulamentações que normatizam os processos de licenciamento ambiental, assim como aquelas que garantem os direitos dos povos e comunidades tradicionais de serem consultados de forma livre, prévia e informada.

\section{REFERÊNCIAS BIBLIOGRÁFICAS}

1. ACSELRAD, Henri. Desregulação, deslocalização e conflito ambiental: considerações sobre o controle das demandas sociais. In: ALMEIDA, Alfredo Wagner Berno de et al. Capitalismo globalizado e recursos territoriais. Rio de Janeiro: Lamparina, 2010. p. 179-209.

2. ALMEIDA, Alfredo Wagner Berno de et al. (org.). Cadernos de debates Nova Cartografia Social: territórios quilombolas e conflitos. Manaus: UEA, 2010.

3. ALMEIDA, Alfredo Wagner Berno de et al. Mineração e garimpo em terras tradicionalmente ocupadas: conflitos sociais e mobilizações étnicas. Manaus: UEA, 2019.

4. ALMEIDA, Alfredo Wagner Berno de. Quilombolas e novas etnias. Manaus: UEA, 2011. 
5. ALMEIDA, Alfredo Wagner Berno de. Terras de quilombo, terras indígenas, "babaçuais livres", "castanhais do povo" faxinais e fundos de pastos: terras tradicionalmente ocupadas. 2. ed. Manaus: Ufam, 2008.

6. ALMEIDA, Alfredo Wagner Berno de; DOURADO, Sheila Borges (org.). Consulta e participação: a crítica à metáfora da teia de aranha. Manaus: UEA, 2013.

7. ARRUTI, José Mauricio. Mocambo: antropologia e história do processo de formação quilombola. Bauru: Edusc, 2006.

8. BESER, Erika; CARVALHO, Luciana. Mineração em territórios quilombolas: notas sobre uma consulta prévia em Trombetas, Oriximiná-PA. Novos Cadernos NAEA, Belém, v. 21, n. 3, p. 119-142, 2018.

9. BRASIL. Ministério de Minas e Energia. Eixo transmissão. Brasília, DF: MME, 2001. Disponível em: https://bit.ly/396LzUd. Acesso em: 14 jul. 2020

10. BRONZ, Deborah. Participação ou consulta? Práticas de negociação e políticas de compensação na implantação de projetos industriais no Brasil: o caso dos “pescadores do petróleo". In: Heredia, Beatriz; ROSATO, Ana (org.). Política, instituciones y gobierno: abordajes y perspectivas antropológicas sobre el hacer política. Buenos Aires: Antropofagia, 2009. p. 257-284.

11. CASTRO, Edna Maria Ramos de; HÉBETTE, Jean (org.). Na trilha dos grandes projetos: modernização e conflitos na Amazônia. Belém: Editora UFPA, 1989.

12. DUMONT, Louis. Homo hierarchicus. Paris: Gallimard, 1966.

13. DUPRAT, Deborah. A convenção 169 da OIT e o direito à consulta prévia, livre e informada. Revista Culturas Jurídicas, Niterói, v. 1, n. 1, p. 51-72, 2014.

14. FRASER, Nancy; HONNETH, Axel. Redistribution or recognition?: A politicalphilosophical exchange. London: Verso, 2003.

15. GLASS, Verena (org.). Protocolos de consulta prévia e o direito à livre determinação. São Paulo: Fundação Rosa Luxemburgo: Cepedis, 2019.

16. KANT DE LIMA, Roberto. A polícia na cidade do Rio de Janeiro: seus dilemas e paradoxos. 2. ed. Rio de Janeiro: Forense, 1995.

17. KYMLICKA, Will. Ciudadanía multicultural. Barcelona: Paidós, 1995.

18. LEITE, Ilka Boaventura. O projeto político quilombola: desafios, conquistas e impasses atuais. Estudos Feministas, Florianópolis, v. 16, n. 3, P. 965-977, 2008.

19. LEITE, Ilka Boaventura. Os quilombos no Brasil: questões conceituais e normativas. Etnográfica, Lisboa, v. 4, n. 2, p. 333-354, 2000.

20. LITTLE, Paul E. Amazonia: territorial struggles on perennial frontiers. Baltimore: Johns Hopkins University Press, 2001. 
21. MOTA, Fabio Reis. Cidadãos em toda parte ou cidadãos à parte: demandas de direitos e reconhecimento no Brasil e na França. Rio de Janeiro: Consequência, 2014.

22. NACIONES UNIDAS. Asamblea General. Promoción y protección de todos los derechos humanos, civiles, políticos, económicos, sociales y culturales, incluido el derecho al desarrollo: informe del Relator Especial sobre la situación de los derechos humanos y las libertades fundamentales de los indígenas, James Anaya. Nueva York: NU, 2009. Disponível em: https://bit.ly/2DJP8UJ. Acesso em: 24 jan. 2020.

23. OLIVEIRA, Luís R. Cardoso de. Direito legal e insulto moral: dilemas da cidadania no Brasil, Quebec e EUA. Rio de Janeiro: Relume Dumará, 2002.

24. ORGANIZAÇÃO INTERNACIONAL DO TRABALHO. Convenção $\mathbf{n}^{\circ} \mathbf{1 6 9}$ sobre povos indígenas e tribais e Resolução referente à ação da OIT. Brasília, DF: OIT, 2011.

25. ROJAS GARZÓN, Biviany; YAMADA, Erika M.; OLIVEIRA, Rodrigo. Direito à consulta e consentimento de povos indígenas, quilombolas e comunidades tradicionais. São Paulo: Rede de Cooperação Amazônica; Washington, DC: Due Process of Law Foundation, 2016.

26. ROSSITO, Flavia Donini et al. Quilombolas e outros povos tradicionais. Curitiba: Cepedis, 2019.

27. SILVA, Liana Amin Lima da. Parecer sobre a implementação da consulta prévia na América Latina. In: SOUZA FILHO, Carlos Frederico Marés de; ROSSITO, Flavia Donini (org.). Estudos sobre o cadastro ambiental rural (CAR) e consulta prévia: povos tradicionais. Curitiba: Letra da Lei, 2016. p. 71-112.

28. ZHOURI, Andréa et al. O desastre do rio Doce: entre as políticas de reparação e a gestão das afetações. In: ZHOURI, Andréa (org.). Mineração, violências e resistências. Marabá: iGuana, 2018. p. 28-64.

29. ZHOURI, Andréa. Justiça ambiental, diversidade cultural e accountability: desafios para a governança ambiental. Revista Brasileira de Ciências Sociais, São Paulo, v. 23, n. 68 , p. $97-107,2008$.

30. ZHOURI, Andréa; LASCHEFSKI, Klemens; PAIVA, Angela. Uma sociologia do licenciamento ambiental: o caso das hidrelétricas em Minas Gerais. In: ZHOURI, Andréa; LASCHEFSKI. Klemens; PEREIRA, Doralice (org.). A insustentável leveza da política ambiental: desenvolvimento e conflitos socioambientais. Belo Horizonte, Autêntica, 2005. v. 1, p. 89-116. 